\title{
Clinical Analysis of NICU Oxygen Therapy over 28 Days in a Single Center
}

\author{
Fujian Shi ${ }^{1}$, Upendra yadav ${ }^{1}$, Xiaofang $\mathrm{Zhu}^{2}$ \\ ${ }^{1}$ The Second Clinical Medical College of Yangtze University, Jingzhou 434020, Hubei, China; \\ ${ }^{2}$ Department of Neonatology, Jingzhou Central Hospital affiliated to Yangtze University, Jingzhou 434020, Hubei, China \\ DOI: $10.32629 / \mathrm{jcmr} . v 2 \mathrm{i} 4.553$
}

\begin{abstract}
Objective - To investigate the main causes, related factors and clinical outcomes of neonates with continuous oxygen therapy $\geq 28$ days in neonatal intensive care unit (NICU) of our hospital. Methods - Clinical data of neonates admitted to NICU from January 2015 to December 2020 who needed continuous oxygen therapy $\geqslant 28$ days after birth were retrospectively analyzed. The causes of continuous oxygen therapy $\geqslant 28$ days, general condition with oxygen and respiratory support, duration and clinical outcomes were recorded. Independent samples $t$ test, Mann-Whitney rank sum test, $x^{2}$ test were used for statistical analysis. Results - In the past 6 years, 115 cases met the inclusion criteria and who received continuous oxyogen therapy $\geqslant 28$ days after birth. 1 . Gestational age: $25^{+1} \sim 40^{+0},<32$ weeks of gestation accounted for $83.5 \%$. The peak gestational age occurred at $28^{+0} \sim 29^{+6}$ weeks after continuous oxygen therapy for $\geqslant 28$ days. 2 . Main causes: 37 cases (32.2\%) of bronchopulmonary dysplasia (BPD), 36 cases (31.3\%) of neonatal pneumonia, 20 cases (17.4\%) of apnea of prematurity (AOP), Pulmonary hypertension was reported in 8 cases (7.0\%), laryngotrachealacia in 2 cases (1.7\%), cyanosis congenital heart disease in 4 cases (3.5\%), and other causes in 8 cases (7.0\%). 3. Short-term prognosis: of 105 premature infants, 90 were successfully deoxygenated, accounting for $85.7 \%$; In 10 cases, 5 cases $(50 \%)$ were successfully deoxygenated. 20 cases gave up treatment or died. 4. Long-term oxygen therapy was related to gestational age and duration of ventilator. The younger the gestational age, the longer the mechanical ventilation time and the longer the total oxygen therapy time $(\mathrm{P}<0.05)$. Conclusion - Continuous oxygen therapy $\geqslant 28$ days received in all gestational age group. Preterm infants with gestational age $<32$ weeks had the highest incidence. The main causes of premature infants with gestational age $<32$ weeks are BPD, neonatal pneumonia, AOP and pulmonary hypertension. Neonatal pneumonia was the main cause in preterm infants with gestational age $32^{+0} \sim 34^{+6}$ weeks, and congenital dysplasia and genetic metabolic diseases were the main cause in neonates above 35 weeks gestational age group.
\end{abstract}

Keywords: NICU, continuous oxygen therapy $\geqslant 28$ days, cause, risk factors

Hypoxemia is a common clinical manifestation of critically ill neonates. Oxygen therapy is the most important method to treat hypoxemia. Neonates who need oxygen therapy for a long time due to various reasons will significantly increase the length of hospital stay, cost consumption and risk of nosocomial infection. Approved by the hospital ethics Committee, this study retrospectively analyzed the etiological distribution, clinical characteristics and high risk factors of neonates with continuous oxygen therapy $\geqslant 28$ days in Jingzhou Central Hospital in the past 6 years, as shown below.

\section{Objects and methods}

\subsection{Subjects}

All neonates admitted to NICU of our hospital from January 2015 to December 2020. The inclusion criteria should meet the following three conditions: (1) start oxygen therapy immediately after birth; (2) duration of continuous oxygen therapy $\geqslant$ 28 days; (3) complete clinical data. The exclusion criteria met one of the following: (1) Death or abandonment of treatment within 28 days after birth (2) incomplete clinical data.

\subsection{Data collection}

The following indicators of the included cases were collected: (1) General information: admission age, sex, gestational age (GA), birth weight (BW); (2) Diagnosis and treatment data: main diagnosis, oxygen therapy method, ventilator support method and time, imaging data, postmenopausal age (PMA)36 weeks respiratory support method and oxygen concentration, final deoxidation and outcome. 


\subsection{Main diagnostic criteria for BPD}

(1) two diagnostic criteria for BPD: NICHD 2001 and 2018 definition and grading criteria for BPD ${ }^{[1-2]}$, In this study, BPD was diagnosed in 2018. (2)Diagnosis of other diseases: Refer to "Practical Neonatology" (5th edition) ${ }^{[3]}$.

\subsection{Statistical methods}

SPSS23.0 software was used for statistical analysis, counting data were expressed as N (\%), and comparison between groups was performed using $x^{2}$ test or continuous calibration chi-square. The measurement data conforming to the normal distribution were represented by $(\mathrm{x} \pm \mathrm{S})$, and the non-conforming data were represented by M (P25, P75). Independent sample T-test was performed for measurement data conforming to normality and homogeneity of variance; otherwise, MannWhitney rank-sum test was performed. $\mathrm{P}<0.05$ was considered statistically significant.

\section{Results}

\subsection{Selected cases}

During the study period, 4698 neonates were admitted to NICU, including 2239 preterm infants, 372 gestational age $<32$ weeks, and 2459 term infants. A total of 640 neonates were eligible for postnatal oxygen use and survival time $\geqslant 28$ days, including 125 neonates with continuous oxygen therapy $\geqslant 28$ days, and 115 cases were selected after excluding 10 cases with incomplete clinical data.

\subsection{Gestational age distribution and oxygen therapy}

Among the 115 cases included, 105 were premature and 10 were term infants. The distribution of different gestational ages, oxygen treatment time, lung consolidation and final deoxygenation were shown in Table 1 . At $25^{+0} \sim 31^{+6}$ weeks gestational age group, 96 cases $(83.5 \%)$ were deoxygenated successfully, 83 cases $(86.5 \%)$. The peak gestational age of long-term oxygen uptake was from $28^{+0}$ to $29^{+6}$ weeks in 63 cases $(54.8 \%)$, of which 54 cases $(85.7 \%)$ were successfully deoxygenated. 10 cases (8.7\%) were over 37 weeks, and 5 cases (50\%) were successfully deoxygenated.

Table 1. Gestational age, oxygen treatment time, lung consolidation and deoxygenation of 115 neonates (n, \%)

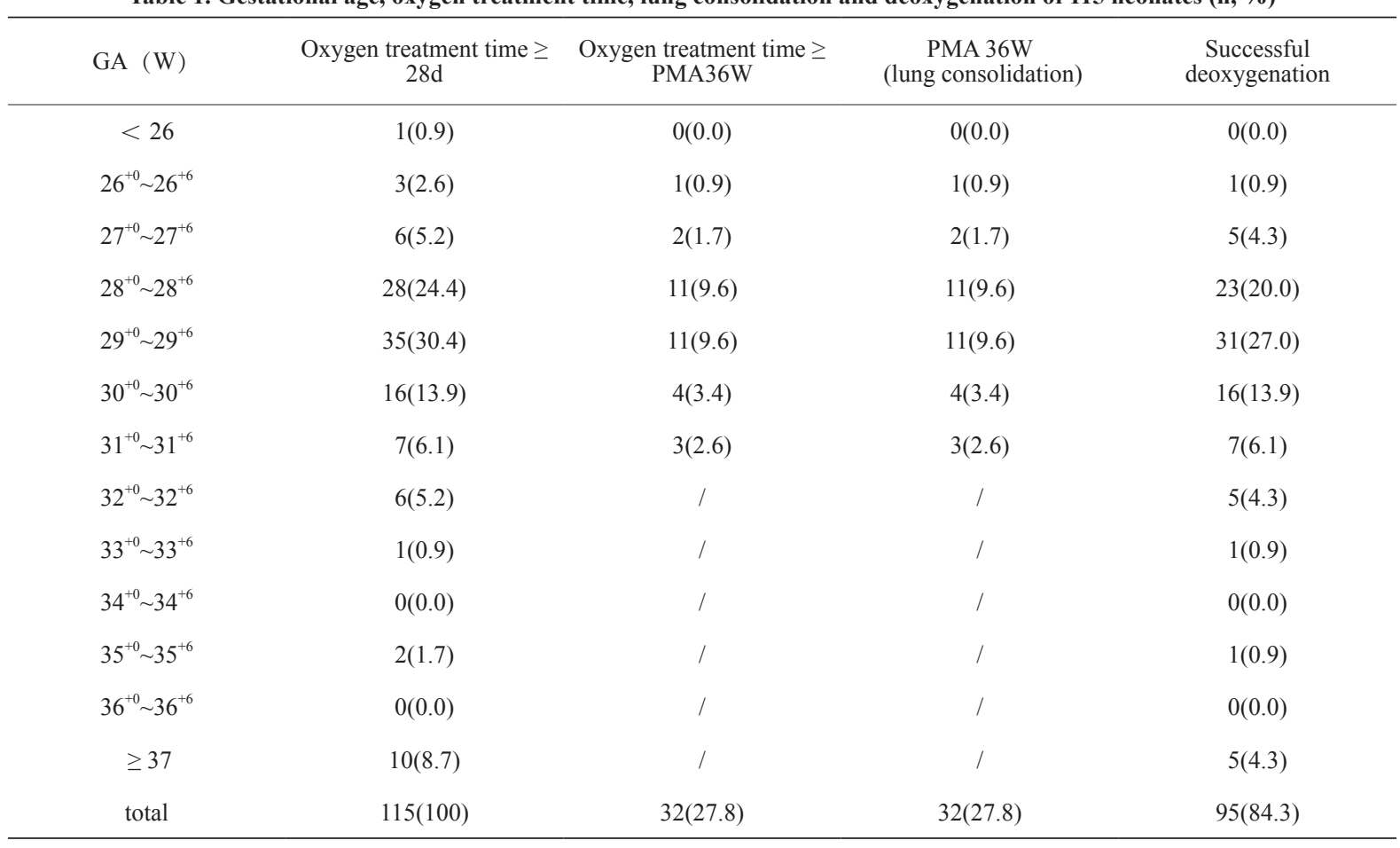

\subsection{Main causes of oxygen therapy $\geqslant 28$ days}

Table 2 shows that the main causes were BPD in 37 cases (32.2\%), neonatal pneumonia in 36 cases (31.3\%), AOP in 20 cases $(17.4 \%)$, pulmonary hypertension in 8 cases $(7.0 \%)$, congenital laryngotrachealacia in 2 cases $(1.7 \%)$, severe cleft lip and palate, incomplete atresia of posterior nostril, congenital laryngeal cyst, congenital glottic stenosis, and congenital cystadenoma of lung, congenital diaphragmatic hernia, epileptic encephalopathy, aortic valve stenosis, complete pulmonary 
venous drainage with atrial septal defect, right ventricular double outlet with ventricular septal defect, persistent trunk artery, and glycogen storage disease type II, 1 each, a total of 12 cases (10.4\%). There were 20 cases of abandonment or death, including 12 cases of BPD, 4 cases of cyanosis congenital heart disease, 1 case of congenital diaphragmatic hernia, 1 case of pulmonary hypertension, 1 case of epileptic encephalopathy, and 1 case of glycogen storage disease II. The main causes of premature infants with gestational age $<32$ weeks were BPD, neonatal pneumonia, AOP and pulmonary hypertension. Neonatal pneumonia was the main cause of preterm infants at $32^{+0} \sim 34^{+6}$ weeks gestational age group, and congenital dysplasia was the main cause of neonates above 35 weeks gestational age group.

Table 2. Main causes of oxygen therapy $\geq 28$ days in 115 neonates

\begin{tabular}{|c|c|c|c|}
\hline Cause & $\begin{array}{l}\text { The number of cases } \\
(\mathrm{n}, \%)\end{array}$ & $\begin{array}{l}\text { Give up or die } \\
(\mathrm{n}, \%)\end{array}$ & GA $(W)$ \\
\hline $\mathrm{BPD}$ & $37(32.2)$ & $12(10.4)$ & $<32$ \\
\hline Neonatal pneumonia & $36(31.3)$ & $0(0.0)$ & $<35$ \\
\hline Severe cleft lip and palate & $1(0.9)$ & $0(0.0)$ & $30^{+1}$ \\
\hline Incomplete atresia of posterior nostril & $1(0.9)$ & $0(0.0)$ & $39^{+5}$ \\
\hline Congenital laryngotracheomalacia & $2(1.7)$ & $0(0.0)$ & $38^{+4}, 35^{+4}$ \\
\hline Congenital laryngeal cyst & $1(0.9)$ & $0(0.0)$ & 39 \\
\hline Congenital glottis stenosis & $1(0.9)$ & $0(0.0)$ & 39 \\
\hline \multicolumn{4}{|l|}{ Congenital cystadenoma of } \\
\hline lung & $1(0.9)$ & $0(0.0)$ & $38^{+2}$ \\
\hline Congenital diaphragmatic hernia & $1(0.9)$ & $1(0.9)$ & $38^{+4}$ \\
\hline $\mathrm{AOP}$ & $20(17.4)$ & $0(0.0)$ & $<32$ \\
\hline Epileptic encephalopathy & $1(0.9)$ & $1(0.9)$ & $35^{+1}$ \\
\hline Pulmonary hypertension & $8(7.0)$ & $1(0.9)$ & $<32$ \\
\hline Aortic stenosis & $1(0.9)$ & $1(0.9)$ & $32^{+2}$ \\
\hline $\begin{array}{l}\text { Complete pulmonary vein } \\
\text { drainage with atrial septal defect }\end{array}$ & $1(0.9)$ & $1(0.9)$ & $37^{+1}$ \\
\hline $\begin{array}{l}\text { Right ventricular double outlet with ventricular } \\
\text { septal defect }\end{array}$ & $1(0.9)$ & $1(0.9)$ & $38^{+2}$ \\
\hline Permanent trunk & $1(0.9)$ & $1(0.9)$ & $38^{+4}$ \\
\hline Glycogen storage disease type II & $1(0.9)$ & $1(0.9)$ & 40 \\
\hline total & $115(100)$ & $20(17.4)$ & \\
\hline
\end{tabular}

\subsection{Oxygen therapy and mechanical ventilation}

GA, BW, total oxygen therapy time and mechanical ventilation time of the enrolled neonates were shown in Table 3 . Among 115 cases, 46 cases needed IMV, and 18 cases (39.1\%) needed IMV in the $28^{+0} \sim 29^{+6}$ gestational age group. The IMV time in $<28$ weeks gestational age group was longer than that in $28^{+0} \sim 29^{+6}$ weeks gestational age group and other gestational age groups, and there was no statistical significance between NIV time in $<28$ and $28^{+0} \sim 29^{+6}$ weeks gestational age group $(\mathrm{P}>0.05)$. There was statistically significant difference between NIV time in $<29^{+6}$ and over $30^{+0}$ weeks gestational age groups $(\mathrm{P}<0.05)$.It can be seen that the younger the gestational age, the longer the mechanical ventilation time, the longer 
the total oxygen therapy time.

Table 3. Oxygen therapy and mechanical ventilation of 115 neonates

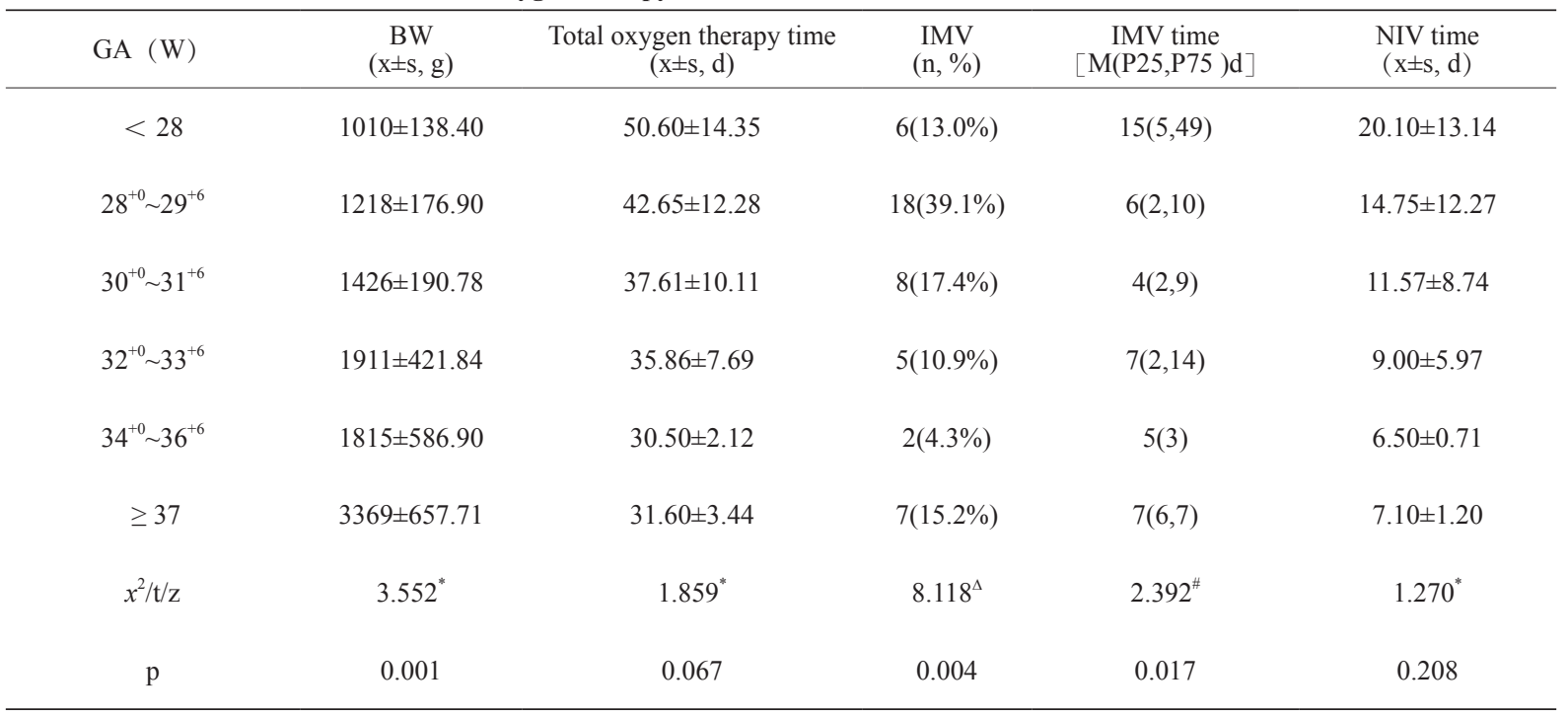

Note: IMV: invasive mechanical ventilation; NIV: non-invasive mechanical ventilation; $\Delta x^{2}$ values, ${ }^{*} \mathrm{t}$ values, ${ }^{\sharp} \mathrm{Z}$ values were compared between $<28$ and $28^{+0} \sim 29^{+6}$ weeks gestational age groups.

\section{Discussion}

Oxygen therapy is a necessary treatment for neonates with hypoxemia. Improper oxygen therapy at the early stage of the disease may lead to hyperoxygen injury and related complications ${ }^{[4]}$, but after entering the stable period, there are still a variety of different reasons will lead to neonates unable to deoxygenate, hospitalization time, cost consumption, nosocomial infection risk will significantly increase. What are the main causes of long-term oxygen uptake in neonates? What are the clinical features? What is the immediate prognosis? At present, there are few research reports at home and abroad, and most of the reported research objects are focused on children. OLIVEIRA et al. ${ }^{[5]}$ reported in a study in 2014 that the main cause of long-term oxygen therapy (out-of-hospital home oxygen therapy) in children was BPD (53.5\%), This was followed by bronchiolitis obliterans (14.0\%), neurological diseases (10.5\%), cystic fibrosis (8.1\%), miscellaneous syndromes $(5.8 \%)$, sickle cell disease $(3.5 \%)$, other neonatal lung diseases $(2.3 \%)$ and interstitial lung diseases $(2.3 \%)$. The authors paid attention to long-term oxygen therapy initiated during the neonatal period.

\subsection{Gestational age distribution of neonates with long-term oxygen therapy}

Among the 115 cases in the observation group, 105 cases $(91.3 \%)$ were preterm with gestational age $<37$ weeks, including 96 cases at $25^{+0} \sim 31^{+6}$ weeks gestational age, accounting for $83.5 \%$. The gestational age peaked at $28^{+0} \sim 29^{+6}$ weeks, 63 cases ( 28 cases at $28^{+0} \sim 28^{+6}$ weeks gestational age, 35 cases at $29^{+0} \sim 29^{+6}$ weeks gestational age), accounting for $60 \%$. Gestational age $<28$ weeks occurred in 10 cases $(9.5 \%)$, and the low proportion was related to the low birth rate of neonates with $<28$ weeks gestational age and thus fewer neonates were enrolled. The younger the gestational age (especially the gestational age $<28$ weeks) and the lower BW, the higher the risk of lung injury caused by exposure to hyperoxygen ${ }^{[2]}$ and mechanical ventilation during the tubule or vesicle stage of lung development, and the more likely to develop chronic lung disease and the need for long-term oxygen therapy ${ }^{[6]}$, which is consistent with the conclusions of POPOVA et al. In addition to the premature infants, table 1 shows that there were 10 cases $(8.7 \%)$ with gestational age $\geqslant 37$ weeks, and the gestational age ranged from 37 weeks to 40 weeks, indicating that long-term oxygen therapy can occur in any gestational age group. In addition to extremely premature infants, other gestational age groups also need to be paid attention to.

\subsection{Distribution of etiology}

In this paper, the etiology of neonates receiving oxygen therapy $\geqslant 28$ days was mainly distributed in respiratory system (73.1\%), nervous system $(18.3 \%)$, circulatory system $(10.4 \%)$ and genetic metabolic diseases $(0.9 \%)$. BPD was 37 cases of respiratory diseases, accounting for $32.2 \%$. LUNA et $\mathrm{al}^{[8]}$ also reported that this disease was the most common cause of longterm oxygen therapy in neonates. There were 36 cases of neonatal pneumonia, including 4 cases of congenital pneumonia and 32 cases of postnatal infectious pneumonia. The gestational age was less than 35 weeks. According to the 2001 diagnostic 
criteria for BPD, these neonates are often diagnosed with BPD. LIU et a ${ }^{[9]}$ reported that lung ultrasound confirmed that some neonates diagnosed with BPD in the past did not actually have BPD, but other lung diseases such as atelectasis, pneumonia, severe pulmonary edema, pulmonary edema with focal lung consolidation and so on, which was also confirmed in this study. There were 20 cases of primary AOP. AOP induced paroxysmal hypoxemia is also a common cause of longterm oxygen therapy ${ }^{[10]}$, which should be paid enough attention to.Among the pulmonary developmental malformations, there was 1 congenital cystadenoma, 1 congenital diaphragmatic hernia, 1 severe cleft lip and palate, incomplete atresia of posterior nostril, 1 laryngeal cyst, glottic stenosis, and 2 laryngotracheal malacia. These diseases could cause obstructive upper airway dyspnea and require long-term oxygen therapy ${ }^{[11]}$, which was consistent with the results of LO BUE A et al ${ }^{[12]}$. There were 8 cases of pulmonary hypertension, including 6 cases of secondary pulmonary hypertension and 2 cases of primary pulmonary hypertension. 4 cases of cyanotic congenital heart disease; One case was epileptic encephalopathy and one case was glycogen storage disease type II. It can be seen that congenital dysplasia, defects, genetic metabolic diseases and gene defects are still problems that need to be paid attention to during perinatal period.

In recent years, the diagnostic criteria of BPD have been controversial. In this study, 96 premature infants with gestational age $<32$ weeks had BPD according to the NICHD diagnostic criteria of $2001^{[1]}$, with a morbidity of 96/372(25.8\%) and a fatality rate of 13/96(13.5\%). According to the NICHD diagnostic criteria in $2018^{[2]}$, there were 37 cases (5 cases in this study were classified as BPD III A grade due to persistent substantial pulmonary lesions and respiratory failure between 14 days of postnatal age and PMA 36 weeks ), with a morbidity of 37/372(9.9\%) and a fatality rate of 12/37(32.4\%). The incidence of BPD diagnosed according to the 2018 diagnostic criteria was lower than the 2001 diagnostic criteria, while the fatality rate of BPD was higher than the 2001 diagnostic criteria, which was consistent with the conclusion of Wang Chenhong et al ${ }^{[13]}$.In this paper, two diagnostic criteria were adopted for comparison, which was closer to the clinical and pathological characteristics of neonates with BPD and infectious pneumonia, and avoided missed diagnosis and misdiagnosis. For premature infants, BPD and pneumonia are still the main causes of long-term oxygen therapy.

\subsection{Relationship between long-term oxygen therapy and mechanical ventilation}

This study showed that the younger the gestational age, the longer the mechanical ventilation time, the longer the total oxygen therapy time. The younger the gestational age, the less mature the lung development, the higher the incidence of neonatal respiratory distress syndrome, such neonates often need invasive and non-invasive respiratory support ${ }^{[14]}$. Mechanical ventilation can cause lung injuries such as barometric injury, volume injury, collapse injury, flow injury and chemical injury in neonates ${ }^{[15]}$, which can trigger inflammation and oxidative stress response, and then damage the alveoli and pulmonary blood vessels in neonates, promote the occurrence of BPD ${ }^{[16]}$, and ultimately lead to the occurrence of longterm oxygen therapy. BRENER et al ${ }^{[17]}$. pointed out that mechanical ventilation is a high risk factor for BPD.

\subsection{Short-term prognosis}

Deoxygenation rate: in this case, the deoxygenation rate of full-term infants was 5/10(50.0\%), the deoxygenation rate of preterm infants was 90/105 (85.7\%), and those without deoxygenation all gave up or died. The etiology of full-term infants was more complicated than that of preterm infants, and most of them were congenital factors, so the deoxygenation rate $(50.0 \%)$ was lower and the prognosis was worse. Premature infants, especially those with gestational age $<32$ weeks, have a high incidence of oxygen therapy $\geqslant 28$ days, but the final outcome is optimistic. Mortality: Of the 115 neonates in this paper, a total of 20 gave up or died. Among them, 37 patients were diagnosed as BPD, and 12 died (10.4\%). There were 36 cases of neonatal pneumonia, and 0 cases died. One case of congenital cystadenoma of lung was discharged after operation. One case with congenital diaphragmatic hernia died of pulmonary dysplasia. Severe cleft lip and palate, posterior nostril incomplete atresia, laryngeal cyst, glottic stenosis, 2 laryngotrachealacia, 0 death. Pulmonary hypertension was reported in 8 patients, and 1 patient died. Four cases of cyanotic preheart died after giving up treatment. There was 1 case of epileptic encephalopathy and 1 case of glycogen storage disease type II. The death cases may be related to the severe condition, poor prognosis, difficult treatment and low willingness of family members to treat.

In conclusion, oxygen therapy $\geqslant 28$ days can occur in any gestational age group, but the causes of long-term oxygen therapy are different in different gestational ages. The main cause of premature infants under 32 weeks of gestational age is still BPD, the main cause of premature infants between $32^{+0}$ and $34^{+6}$ weeks gestational age is neonatal pneumonia, and the main cause of premature infants over 35 weeks gestational age and full term infants is congenital dysplasia and genetic metabolic diseases. According to different gestational ages, it is still a long way to take active measures to prevent preterm birth, reduce the duration of mechanical ventilation, prevent infection, strengthen screening and health care during pregnancy, so as to reduce congenital developmental abnormalities, etc. 


\section{References}

[1] JOBE AH B E. Bronchopulmonary dysplasia[J]. Am J Respir Crit Care Med, 2001, 7(163): 1723-1729.

[2] HIGGINS R D, JOBE A H, KOSO-THOMAS M, et al. Bronchopulmonary Dysplasia: Executive Summary of a Workshop[J]. The Journal of pediatrics, 2018, 197: 300-308.

[3] Shao Xiaomei, Ye Hongmao, QIU Xiaoshan. Practical neonatology [M]. 5th ed. Beijing: People's Medical Publishing House, 2019.

[4] HIGGINS R D, BANCALARI E, WILLINGER M, et al. Executive summary of the workshop on oxygen in neonatal therapies: controversies and opportunities for research[J]. Pediatrics (Evanston), 2007, 119(4): 790.

[5] OLIVEIRA L, COELHO J, FERREIRA R, et al. Oxigenoterapia Domiciliária de Lonag Duração na Criança: Evidências e Questões em Aberto[J]. Acta médica portuguesa, 2014, 27(6): 717.

[6] LIGNELLI E, PALUMBO F, MYTI D, et al. Recent advances in our understanding of the mechanisms of lung alveolarization and bronchopulmonary dysplasia[J]. American journal of physiology-Lung cellular and molecular physiology, 2019, 317(6): L832-L887.

[7] POPOVA A P. Mechanisms of bronchopulmonary dysplasia[J]. Journal of cell commun cation and signaling, 2013, 72(2): 119-127.

[8] LUNA PAREDES M C, ASENSIO DE LA CRUZ O, CORTELL AZNAR I, et al. Fundamentos de la oxigenoterapia en situaciones agudas y crónicas: indicaciones, métodos, controles y seguimiento[J]. Anales de pediatría (Barcelona, Spain: 2003), 2009, 71(2): 161-174.

[9] LIU J, CHEN S, LIU F, et al. BPD, Not BPD, or iatrogenic BPD: findings of lung ultrasound examinations[J]. Medicine (Baltimore), 2014, 93(23): e133.

[10] HAYES D J, WILSON K C, KRIVCHENIA K, et al. Home Oxygen Therapy for Neonates. An Official American Thoracic Society Clinical Practice Guideline[J]. Am J Respir Crit Care Med, 2019, 199(3): e5-e23.

[11] Ones KL.Dysmolphology approach and classification[M]//Smith's Recognizable Patterns of Human Malformation.7th ed. Elsevier Saunders, Philadelphia, 2013: 1.

[12] LO BUE A, SALVAGGIO A, INSALACO G. Obstructive sleep apnea in developmental age. A narrative review[J]. European journal of pediatrics, 2020, 179(3): 357-365.

[13] WANG Chenhong, SHEN Xiaoxia, Chen Mingyan, et al. Diagnosis and prognosis of bronchopulmonary dysplasia in premature infants with different diagnostic criteria [J]. Chin J pediatr, 2020, 58(5): 381-386.

[14] ARSAN S, KORKMAZ A, OGUZ S. Turkish Neonatal Society guideline on prevention and management of bronchopulmonary dysplasia[J]. Türk Pediatri Arşivi, 2019, 53(sup1): 138-150.

[15] KATIRA B H. Ventilator-Induced Lung Injury: Classic and Novel Concepts[J]. Respiratory Care, 2019, 64(6): 629637.

[16] BALANY J, BHANDARI V. Understanding the Impact of Infection, Inflammation, and and Their Persistence in the Pathogenesis of Bronchopulmonary Dysplasia[J]. Frontiers in Medicine, 2015, 2.

[17] BRENER D P, NINO G Y, GALLETTI M F, et al. Bronchopulmonary dysplasia: incidence and risk factors[J]. Arch Argent Pediatr, 2017, 115(5): 476-482. 